\title{
Quality of Life among Elderly Patients with Chronic Liver Diseases at Al-Rajhy Liver Hospital, Assiut University
}

\author{
Zeinab Shaker Abdullah ${ }^{1}$, Nermeen Mahmoud Abd El-aziz ${ }^{2}$, Mohammed Ahmed Medhat ${ }^{3}$. \\ 1. Clinical Demonstrator in Gerontological Nursing, Faculty of Nursing, Assiut University. Egypt. \\ 2. Assistant Professor of Gerontological Nursing, Faculty of Nursing, Assiut University. Egypt. \\ ${ }^{3 .}$ Lecturer of Tropical Medicine and Gastroenterology, Faculty of Medicine, Assiut University. Egypt.
}

\begin{abstract}
Background: Chronic liver diseases (CLDs) adversely affect the Quality of life since patients frequently have asthenia, incapacitation, pain in various body parts, a sleeping disorder, lack of appetite, insomnia, and complications related to liver cirrhosis. Study Aim: The study aimed to assess the Quality of life among elderly patients with CLDs at El Rajhy liver hospital. Design: This is a descriptive study conducted for this study. The study sample included 385 elderly patients with chronic liver diseases. Setting: The study was carried out in Al-Rajhy Liver Hospital, Assiut University, Egypt. Two tools were utilized; $1^{\text {st }}$ tool: Structured Interview questionnaire include's personal characteristics and $2^{\text {nd }}$ tool was: Chronic Liver Disease questionnaire (CLDQ) for assessing patients' Quality of life. Results: Around half of the studied sample had moderate impairment of QOL. There was a relationship between QOL \& chronic liver diseases. It has a significant impact on the QOL for elderly patient. Conclusion: Chronic liver diseases have significant negative impact on the QOL among elderly patients in relation to abdominal symptoms, fatigue, systemic symptoms, activity and emotional function. Recommendations: Health educational programs should be initiated to increase knowledge among elderly patients about CLDs and its adverse effects on the elderly quality of life.
\end{abstract}

\section{Keywords: Quality of life, Elderly \& Chronic liver Diseases}

\section{Introduction}

The World's older peoples continue to grow; the number of older persons aged 60 years or over and it is expecting to increase from 962 million in 2017 to 1.4 billion in 2030, with the populace aged 60 or above were developing at a rate of about $3 \%$ per 12 months (World population prospects, 2017). Egypt's total population was $100,995.147$ million in the mid of October 2019, while the 65 years and over represent $5.95 \%$. Also, the Egyptian life expectancy increased in 2019 to become 71.90 years; (68.2 years for males and 73.0 years for females) (Central Intelligence Agency, 2019). Globally, Chronic Liver Diseases (CLDs) is a significant health burden to the community. and it is assessed to be the fifth most regular reason for death after coronary illness, stroke, lung sickness, and malignancy. Also around 500 million people have CLD with a viral etiology (Ghazwan A., 2019).

Chronic liver disease (CLD) refers to a long-term pathological process of continuous destruction of liver parenchyma and its gradual substitution with fibrous tissue, which eventually brings about LC related with a deadly result. Risk factors of CLD incorporate viral (Hepatitis B and C), non-alcoholic steatohepatitis (NASH), stoutness, diabetes mellitus, and the utilization of natural and dietary enhancements, immune system hepatitis, and Wilson infection (Kooffreh et al., 2017).

Despite hepatitis and steatosis are asymptomatic, they can progress to CLD. Hepatitis, a liver inflammation, may lead to cell damage and/or destruction. Repeated cycles of inflammation ;( fibrosis), necrosis, and hepatocellular regeneration contribute to advanced liver cirrhosis (Wong RJ et al., 2016).

The Quality of life is the everyday well-being of persons and societies, outlining negative and tremendous life points. It consists of lifestyle satisfaction, the whole form of bodily health, family, education, employment, wealth, safety, to freedom, spiritual beliefs, and the environment (WHO, 2017).

Chronic liver diseases(CLDs) adversely affect the Quality of life since patients frequently have asthenia, incapacitation, pain in various body parts, a sleeping disorder, lack of appetite, insomnia, and complications related to liver cirrhosis, such as, ascites, varicella seeping in the stomach and throat, and hepatic encephalopathy. Additionally, CLDs connected to job loss, debilitated working, disposition swings, nervousness, low confidence, wretchedness, and other passionate issues that seriously impact on patients' QOL and (Mujica-Mota., et al.,2016).

The role of Gerontological nurse is increasingly likely to encounter patients with advanced liver disease and has a vital role in improving end-of-life care for this 
group. Nurses from all areas of practice must be able to offer adequate nursing counseling and intensive education. Educational interventions are applied as a regular portion of the nursing work; it can be delivered in the form of designed activities, including symptoms management, lifestyle instructions, and behavioral modification. However, before drafting instructions, nurses must understand the educational needs of patients and the factors affecting those needs (Chen et al., 2017). As the mortality and morbidity related to chronic liver diseases and cirrhosis increase, nurses need to develop their knowledge and skills in caring for people who have advanced liver disease (Clements et al.,2018). Therefore, this study was conducted to assess the Quality of life and knowledge among elderly patients with CLDs at El Rajhy liver hospital.

\section{Significance of the study:}

In Egypt the most widely recognized reason for liver cirrhosis was hepatitis $\mathrm{C}$ virus (HCV). Egypt is the country with the highest $\mathrm{HCV}$ prevalence in the world at that time; up to $20 \%$ of the general population is infected. in 2015, the prevalence of $\mathrm{HCV}$ infection in Egypt was $40 \%$ of Egyptians of old age 60 or more years, while $7 \%$ are chronic active hepatitis C patients (Hassanein et al., 2017). Prevalence of hepatitis B virus (HBV) among Egyptians aged 60 years is $1.4 \%$, with low rates of HBV-HCV co-infection $(0.06 \%)$ that leads finally to fibrosis and/or potentially inflammation in the liver (Ismail et al., 2017).

The prevalence of chronic liver diseases is approximately $80 \%$ of the people $\geq 60$ 'years' old at $\mathrm{Al}$ Rajhy Liver Hospital, according to (Statistics office, 2018). Despite the high burden of chronic liver diseases in Egypt, the study of these patients' Quality of life, especially the elderly, received little attention.

Study aim: Assessment of Quality of Life among elderly patients with Chronic Liver Diseases at El Rajhy liver hospital.

Research question: Does Chronic Liver Diseases affect the Quality of Life of elderly patients?

\section{Subjects and Methods:}

Research design: Descriptive cross-sectional research design was used.

Setting: The study was carried out at inpatient ward in El Rajhy liver hospital at Assiut University.

Sample: Convenient sample for all elderly patients with chronic liver diseases male/female was used. The total numbers of elderly patients with CLDs ( $\geq 60$-year old) admitted to Al-Rajhy Liver Hospital at Assiut University, about 4000 patients per year. The estimated sample size was 350 elderly patients aged $\geq 60$-year-old calculating by using EPI /Info software, version 3, 3 with $95 \%$ confidence interval (CI). To compensate for the drop outs, $10 \%$ was added the initially calculated sample size, the final sample size was 385patients.

Study tools: data collected using 2 tools: -

Tool I: Structured Interview questionnaire that consisted of 3 parts: -

The $1^{\text {st }}$ part was included socio-demographic characteristics as, age, sex, residence, marital status, occupation, and level of education, etc. The $2^{\text {nd }}$ part was for elder's past and present medical history of chronic liver diseases such as a family history of the disease, smoking ...etc.

Tool II: Chronic Liver Disease Questionnaire (CLDQ), is a tool developed by (Younossi et al., 1999), and used to measure the Quality of life of patients with chronic liver diseases. It is the first specific instrument for measuring QoL in Chronic liver diseases. It includes 29 items in the following domains: abdominal symptoms, fatigue, systemic symptoms, activity, emotional function and worry.

Abdominal symptoms (AB) questions no. (1, 5, 17) with a total score of 21 , fatigue (FA) questions no. $(2,4,8,11,13)$ with a total score of 35 , systemic symptoms (SY) questions no. (3, 6, 21, 23, 27) with a total score of 35, activity (AC) questions no. (7, 9, 14) with a total score of 21.

Emotional functions (EM) questions no. (10, 12, 15, $16,19,20,24,26)$ with a total score of 56 and worry (WO) questions no. $(18,22,25,28,29)$ with a total score of 35 .

Scoring system: For CLDQ, the grade for items range 29-203 from worst to best (QOL), type of answers ranging from "all of the time" to "none of the time" The total percentage grade was categorized as mild impairment if Quality of life $(<50 \%)$, moderate impairment (50-75\%) and severe impairment if the patient got a score $>75 \%$ (Alghazaly et al., 2016).

Tools Validity:

Tools tested for content validity by a group of three experts in Tropical Medicine and Gastroenterology, and gerontological health nursing and required modifications were done.

Tools Reliability: -

Alpha 'Cronbach's test was used to assess the internal consistency of tool, and it was (Cronbach's $\alpha=0.782$ and, for the CLDQ).

\section{Methods}

I- Preparatory stage: Official letter of endorsement was accomplished from the nursing faculty dean to the director of Al-Rajhy Liver Hospital at Assiut University. The letter incorporated an endorsement to do the study, the nature and purpose of the study.

II- Pilot study: A pilot study was carried out prior to starting of data collection on (35 elderly patients), 
who excluded from the study. To test tools clarity and to assess the needed time for fulfilling it, the necessary modifications based on the result of the pilot study and the questionnaire and was reconstructed to be ready to be use.

III- Ethical Consideration: The Nursing faculty ethical committee approved the research proposal. There was no risk for the study subjects during the carrying out of the research also the clinical research ethical principles were followed in the study. The right of refusing to participate for all elderly participants was assured and they can withdraw at any time from the study without any rationale.

VI- Field work:

The elderly was met by the researchers, and an explanation of the purpose of the research was done to the participants in the study. Face to face individual interview with the elderly was begun, and the questionnaire was completed for all participants.

Data collection was carried out at Al-Rajhy Liver Hospital at Assiut University. With the duration time that started from the $1^{\text {st }}$ of December 2019 and ended on the $30^{\text {th }}$ of September 2020; data were collected from the previously mentioned setting for ten months. The approximate time spent during the filling of sheet was around 30-40 minutes.

V- Statistical analysis: Data entry and data analysis were done using Excel 2016 program and SPSS version 22 (Statistical Package for Social Science). Data were presented as number, percentage, mean, and standard deviation. Chi-square test was used to compare qualitative variables. P-value considered statistically significant when $\mathrm{P}-\leq 0.05$.

\section{Results:}

Table (1): Distribution of studied elderly regarding their socio- demographic characteristics.

\begin{tabular}{|c|c|c|}
\hline Socio-demographic Data & No. (385) & $\%$ \\
\hline \multicolumn{3}{|l|}{ Age: (years) } \\
\hline $60<65$ & 239 & 62.1 \\
\hline$\geq 65$ & 146 & 37.9 \\
\hline Mean \pm SD (Range) & \multicolumn{2}{|c|}{$63.76 \pm 4.49(60.0-83.0)$} \\
\hline \multicolumn{3}{|l|}{ Sex: } \\
\hline Male & 269 & 69.9 \\
\hline Female & 116 & 30.1 \\
\hline \multicolumn{3}{|l|}{ Place of residence: } \\
\hline Urban & 59 & 15.3 \\
\hline Rural & 326 & 84.7 \\
\hline \multicolumn{3}{|l|}{ Marital status: } \\
\hline Single & 4 & 1.0 \\
\hline Married & 341 & 88.6 \\
\hline Widowed & 38 & 9.9 \\
\hline Divorced & 2 & 0.5 \\
\hline \multicolumn{3}{|l|}{ Level of education: } \\
\hline Illiterate & 222 & 57.7 \\
\hline Read and write + Primary & 113 & 29.3 \\
\hline Preparatory & 14 & 3.6 \\
\hline Secondary & 30 & 7.8 \\
\hline University & 6 & 1.6 \\
\hline \multicolumn{3}{|l|}{ Job after the retirement: } \\
\hline No work & 135 & 35.1 \\
\hline Worker + Farmer & 144 & 37.4 \\
\hline Housewife & 106 & 27.5 \\
\hline \multicolumn{3}{|l|}{ Person who supports or lives with: } \\
\hline Husband/ wife & 226 & 58.7 \\
\hline Son/ daughter & 90 & 23.4 \\
\hline Both & 58 & 15.1 \\
\hline Alone & 11 & 2.9 \\
\hline
\end{tabular}




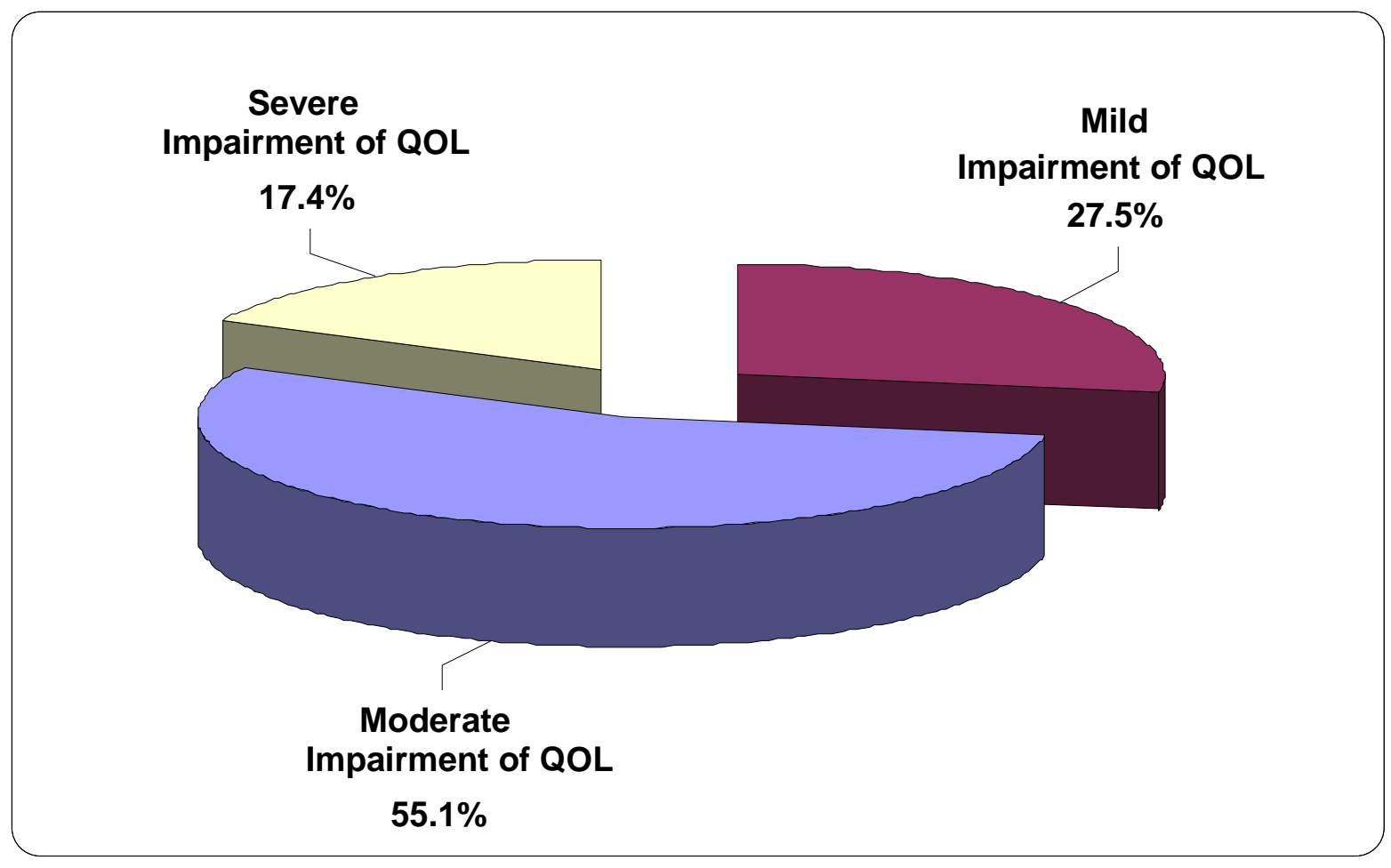

Figure 1: Distribution of total score of Quality Of Life among elderly patients with chronic liver diseases.

Table (2): Relationship between total score of Quality Of Life domain and different type of chronic liver diseases among elderly patients with chronic liver diseases.

\begin{tabular}{|c|c|c|c|c|c|c|c|}
\hline \multirow{3}{*}{ Medical diagnosis } & \multicolumn{6}{|c|}{ Total score (level) } & \multirow{3}{*}{ P-value } \\
\hline & \multicolumn{2}{|c|}{$\begin{array}{c}\text { Mild } \\
\text { Impairment of } \\
\text { QOL } \\
\end{array}$} & \multicolumn{2}{|c|}{$\begin{array}{c}\text { Moderate } \\
\text { Impairment of } \\
\text { QOL } \\
\end{array}$} & \multicolumn{2}{|c|}{$\begin{array}{c}\text { Severe } \\
\text { Impairment of } \\
\text { QOL } \\
\end{array}$} & \\
\hline & No. & $\%$ & No. & $\%$ & No. & $\%$ & \\
\hline Chronic hepatitis B & 4 & $3.8 \%$ & 2 & $0.9 \%$ & 0 & $0.0 \%$ & \multirow{4}{*}{$0.001 *$} \\
\hline Chronic hepatitis C & 23 & $21.7 \%$ & 82 & $38.6 \%$ & 25 & $37.3 \%$ & \\
\hline Liver cirrhosis & 58 & $54.7 \%$ & 83 & $39.2 \%$ & 31 & $46.3 \%$ & \\
\hline Hepatocellular carcinoma & 21 & $19.8 \%$ & 45 & $21.3 \%$ & 11 & $16.4 \%$ & \\
\hline
\end{tabular}

*There is a highly significant difference - Significant at $P<0.05$

Table (3): Relationship between total score of Quality Of Life domain and duration of chronic liver disease among elderly patients with chronic liver diseases.

\begin{tabular}{|c|c|c|c|c|c|}
\hline \multirow{3}{*}{ Total score (level) } & \multicolumn{4}{|c|}{ Duration of disease } & \multirow{3}{*}{ P-value } \\
\hline & \multicolumn{2}{|c|}{$<5$ years } & \multicolumn{2}{|c|}{$\geq 5$ years } & \\
\hline & No. & $\%$ & No. & $\%$ & \\
\hline Mild impairment of QOL & 79 & 37.1 & 27 & 15.7 & \multirow{3}{*}{$0.000 *$} \\
\hline Moderate impairment of QOL & 100 & 46.9 & 112 & 65.1 & \\
\hline Severe impairment of QOL & 34 & 16.0 & 33 & 19.2 & \\
\hline
\end{tabular}

*There is a highly significant difference - Significant at $P<0.05$ 
Table (4): Relationship between total score of Quality Of Life domain and socio- demographic characteristics among elderly patients with chronic liver diseases.

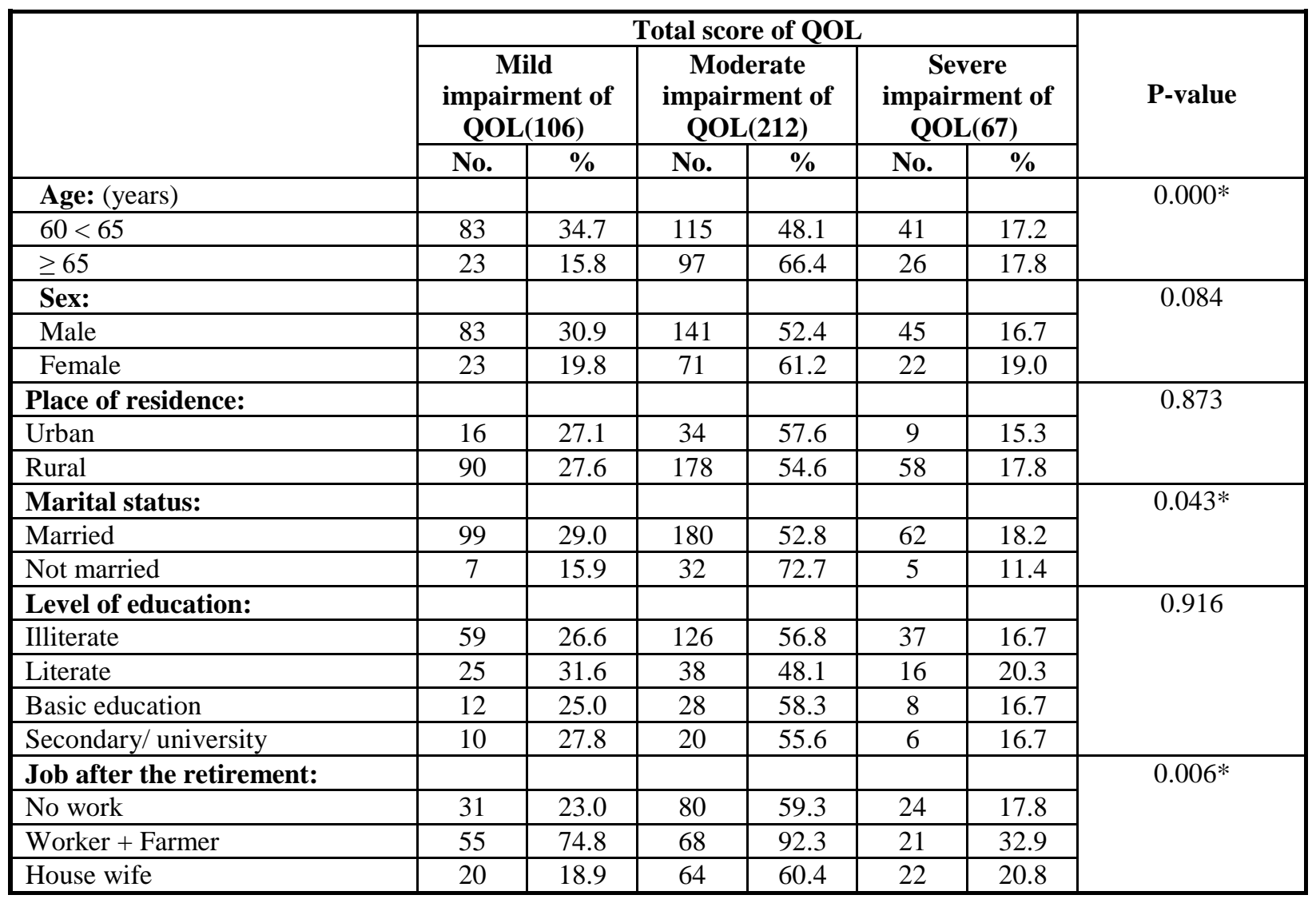

*There is a significant difference - Significant at $P<0.05$

Table (1): Showed that, $62.1 \%$ of them aged (60 - 65) years, while $37.9 \%$ of them aged $(\geq 65)$ years with mean age \pm SD $63.76 \pm 4.49$ (60.0-83.0). Regarding sex, it was observed that $69.9 \%$ of the studied participants were male, while $30.1 \%$ of them were female.

Regarding to residence, it was found that $84.7 \%$ of the participants live in rural areas while $15.3 \%$ of them live in urban areas. Also this table revealed that $57.7 \%$ of the studied samples were illiterate.

Figure (1): Revealed that, $27.5 \%$ of the studied sample were mild impairment those who $<50 \%$ in Quality of life score, while $55.1 \%$ were moderate impairment those who (50-75\%) in Quality of life score and $17.4 \%$ sever impairment who $>75 \%$ in quality of life score.

Table (2): Showed that there was a highly significant difference between different type of chronic liver diseases of the studied sample and total score of QOL with $\mathrm{P}=0.001$.

Table (3): Revealed that there was highly statistical significant difference between total score of QOL and duration of chronic liver diseases with $\mathrm{P}=0.000$.
Table (4): Revealed that there was a highly statistical significant difference between total QOL score and age and marital status and job after the retirement with $\mathrm{P}=0.000, \mathrm{P}=0.000, \mathrm{P}=0.006$ respectively. Also this table illustrated that there was no significant difference between total QOL score of the studied sample with gender, place of residence and level of education with $\mathrm{P}=0.084, \mathrm{P}=0.873, \mathrm{P}=0.916$ respectively.

\section{Discussion}

Chronic liver disease is a significant cause for mortality and morbidity. Recent study proposes that approximately 5.5 million people suffer from CLD worldwide and as many as 40,000 people will die of its natural course or complications. In the United States alone, CLD results in 4000 to 5000 deaths per year and 11,000 to 17,000 hospitalizations. CLD is the twelfth leading cause of death in the United States. Patients with advanced CLD demonstrate a variety of symptoms, several of which interfere with life exercises and quality of life. (Tomohiro K et al., 2018). 
The present study showed that (CLD) about two fifth of the studied sample aged from $(60<65)$ years old, this could be attributed to improvement of diagnostic measures and curable treatment for those aged less than 40 years, have more chances than older adults. With aging, the liver volume diminishes by $20-40 \%$ as one gets older and those aged 65 years or higher indicated an approximately 35\% reduce in the blood volume of the liver compared with those aged less than 40 years., The mean age of the studied sample was $63.76 \pm 4.49$, this is similar to Hee Kim et al., 2016 who reported that age was found to be associated with liver cirrhosis, study participants were in age from $<65$ years with mean age $64.7 \pm 3.8$ years. and most of these patients were men.

The current study revealed that Chronic liver disease more common in males than females as more than two third of the studied sample were male., These results were accordance with Evangelista Sagnelli et al., 2017 who found that, most of the studied sample were male. These may be related to males was smokers, exposed for occupational hazard, risk for addiction were high risk for infection and chronic diseases than females.

The low creation in males of estradiol, a potent antioxidant ready to suppress hepatic fibrosis in creature models and to repress the generation of reactive oxygen species in essential culture Boix et al., 2017. The relationship between quality of life (QOL) score and age among the studied sample it was demonstrated that there was statistical significant difference between quality of life(QOL) score and age of the studied sample $\mathrm{P}=0.000$, as participants aged $60<65$ years' old achieved mild QOL than old ones. this may be related to elderly participants aged $60<65$ years' old followed healthy life style, more knowledgeable, treatment follow up, better diagnostic measures, had good chance and more independent than older ones. This agree with Janani K et al., 2018 who revealed that Quality of life scores decreased with advancing age.

There was a highly statistical significant difference between different type of chronic liver diseases and total score of the studied sample with $\mathrm{p}=0.000$. this may be related to most of elderly participants had liver cirrhosis which causes serious complications that affect quality of life. This study agreed with Labenz et al., 2019 who revealed that quality of life impact according to type of liver disease.

The present study showed that the total QOL decreases with increasing the duration of disease, as $65 \%$ of elderly participants with CLD $>5$ years were moderate impairment of QOL in compared those ones with duration $<5$ years were $46.9 \%$. This study agreed with Rossi et al., 2017 who reported that heath QOL domain diminishes with increasing the duration of disease. This may be related to the longer period of disease, the greater risk for cirrhosis is dependent on the presence or absence of decompensating events (ascites, encephalopathy, and variceal bleeding). The pace of advancement of these events is associated with increased morbidity, mortality, and medical care usage Asrani et al., 2018.

\section{Conclusion:}

On the light of results of the current study and answers of the research questions, it could be concluded that, there was around half of the studied sample had moderate QOL, CLD was a frequent condition among elderly and increased with age and common in male than female. There was statistically significant relation between total scores of Qol of studied sample and their age, marital status, level of education and job after the retirement. CLD deteriorate Quality of life and significantly affected on the domain quality of life score (abdominal symptoms, fatigue, systemic symptoms, activity, and emotional function).

\section{Recommendations:}

- Screening for all individuals above the age of 60 years for early detection of Chronic liver diseases.

- Designed health educational programs should provide to elderly to increase their knowledge about factors attributed with CLDs as: causes, risk factors, treatment, and complications of CLDs can guide actions to reduce and prevent occurrence of disease.

\section{References:}

- Alghazaly G., Mohamed., Abd El Raouf Y. Mahmoud., \& Zaglol K., (2016): Impact of chronic liver disease on Health Related Quality of Life and its association with anemia in AlGharbiyah Governorate, Egypt. Global Advanced Research Journal of Medicine and Medical Sciences Vol. 5(2), Pp: 53- 66.

- Asrani SK, Kouznetsova M, Ogola G, Taylor T, Masica A, Pope B, Trotter J, Kamath $\mathbf{P} \&$ Kanwal F, (2018); Increasing health care burden of chronic liver disease compared with other chronic diseases, 2004-2013. Gastroenterology.; vol.15(5),Pp:719-729.

- Boix R, Cano R, Gallego P, Vallejo F, Fernández-Cuenca R, Noguer I, \& Larrauri A, (2017): Hepatitis C hospitalizations in Spain, 2004-2013: a retrospective epidemiological study. BMC Health.; vol.17 (4), Pp:56-61.

- Central Intelligence Agency, (2019): Egypt Demographics Profile 2018, Available at 
https://www.indexmundi.com/egypt/demographics profile.html

- Chen, M., Hung, H., Chang, H., Yang, S., Tsai, W., \& Chang, S. (2017); Assessment of educational needs and Quality of life of chronic hepatitis patients. BMC health services research; vol.17 (1), Pp: 148.

- Evangelista Sagnelli, Tommaso Strofolini, Caterina Sagnelli, Mario Pirisi, rgio Babudieri, Guido Colloredo,Maurizio Russello,Nicola Copp ola,Giovanni Battista Gaeta,Bruno Cacopardo, Massimo De Luca, \& Piero Luigi Almasio, (2017); Gender differences in chronic liver diseases in two cohorts of 2001 and 2014 in Italy; vol. 5(3), Pp:130-227.

- Ghavimi S., Azimi H., Patel N \& Shulik O. (2019); Geriatric Hepatology: The Hepatic Diseases of the Elderly and Liver Transplant. J Dig Dis Hepatol; Vol. 5(3), Pp: 167.

- Ghazwan A. (2019): Chronic Liver Disease Questionnaire in Duhok City / Kurdistan Region of Iraq Journal of University of Duhok, Vol. 22(2) (Pure and Eng. Sciences), Pp 41-48.

- Hassanein, M., Hady, A., Helal, N., Eltalkawy, M., \& Aboushousha, T. (2017): Comparative study of liver biopsy results in egypt over three decades. DOI: 10.15761/GMO.1000132.

- Hee Kim, Tatiana Kisseleva, \& David A. Brenner (2016): Aging and liver disease, Curr Opin Gastroenterol; vol. 31(3), Pp: 184-191.

- Ismail, SA., Cuadros, DF \& Benova. L (2017): Hepatitis B in Egypt: A cross-sectional analysis of prevalence and risk factors for active infection from a nationwide survey. Liver Int; vol. 3(7), Pp:18141822.

- Janani K, Mayank J., Joy V., Vijaya S., Kavya H., Tom M., \& Jayanthi V. (2018): Health-related Quality of life in liver cirrhosis patients using SF36 and CLDQ questionnaires, vol. 4(4), Pp: 232 239.

- Kooffreh-Ada M., Okpara H., Affiong O., \& Okonkwo U., (2017): Risk factors of chronic liver disease amongst patients receiving care in a Gastroenterology practice in Calabar; vol. 5(2), Pp:98-120.

- Labenz, C., Toenges, G., Schattenberg, J., Nagel, M., Huber, Y., Marquardt, J., \& Wörns, M. (2019): Health-related Quality of life in patients with compensated and decompensated liver cirrhosis. European journal of internal medicine; vol. 70(8), Pp: 54-59.

- Mujica-Mota, R., Roberts, M., Abel, G., Elliott, M., Lyratzopoulos, G., Roland, M \& Campbell, J. (2016): Common patterns of morbidity and multi-morbidity and their impact on health-related
Quality of life: evidence from a national survey. Quality of Life Research; vol. 24(4), Pp: 909-918.

- Rinella ME., (2015): Nonalcoholic fatty liver disease: a systematic review. JAMA; 3(13) Pp:2263-2273.

- Rossi, D., GALANT, L., \& MARRONI, C. (2017): Psychometric property of fatigue severity scale and correlation with depression and Quality of life in cirrhotics. Arquivos de gastroenterologia; vol.54(4), Pp:344-348.

- Sallam, I., (2013): The role of parenteral antischistosomal therapy in the spread of $\mathrm{HCV}$ in Egypt, available at: http://www.PubMed.com

- Statistics office, (2018): statistical office at AlRajhy Liver Hospital at Assiut University.

- Tomohiro, K., \& Nobuhiro O. (2018): Role of Platelet, Blood Stem Cell, and Thrombopoietin in Liver Regeneration, Liver Cirrhosis, and Liver Diseases; vol. 46 (1), pp. 159-177.

- WHO World Health Organization (2017): available

http://www.who.int/healthinfo/survey/whoqolqualit yoflife/en/index 4.html.

- Wong RJ., Aguilar M., Cheung R., Perumpail RB., Harrison SA \& Younossi ZM (2015): Nonalcoholic steatohepatitis is the second leading etiology of liver disease among adults awaiting liver transplantation in the United States. Gastroenterology; vol. 14 (8), Pp: 547-555.

- World Population Prospects, (2017): Ageing. Available at:- http://www.un.org/en/sections/issuesdepth/ageing/

- Younossi ZM., Boparai N., Price LL., Kiwi ML., McCormick M. \& Guyatt G. (1999): Healthrelated Quality of life in chronic liver disease: the impact of type and severity of disease. Am J Gastroenterol; vol. 96(2), Pp: 2199-2205.

- Yukio K., Kazuhiro K., Kozo T. \& Nobuhisa F(2017): The Effectiveness of a Liver Disease Education Class for Providing Information to Patients and Their Families; vol.9(3),Pp: 207-212. 